\title{
Hallmarks of glycosylation in cancer
}

\author{
Jennifer Munkley ${ }^{1}$ and David J. Elliott ${ }^{1}$ \\ ${ }^{1}$ Institute of Genetic Medicine, Newcastle University, Newcastle-upon-Tyne, NE1 3BZ, UK \\ Correspondence to: Jennifer Munkley, email: jennifer.munkley@ncl.ac.uk \\ Keywords: cancer, glycosylation, hallmarks, glycans, aberrant \\ Received: January 28, $2016 \quad$ Accepted: March 02, $2016 \quad$ Published: March 17, 2016
}

\section{ABSTRACT}

\begin{abstract}
Aberrant glycosylation plays a fundamental role in key pathological steps of tumour development and progression. Glycans have roles in cancer cell signalling, tumour cell dissociation and invasion, cell-matrix interactions, angiogenesis, metastasis and immune modulation. Aberrant glycosylation is often cited as a 'hallmark of cancer' but is notably absent from both the original hallmarks of cancer and from the next generation of emerging hallmarks. This review discusses how glycosylation is clearly an enabling characteristic that is causally associated with the acquisition of all the hallmark capabilities. Rather than aberrant glycosylation being itself a hallmark of cancer, another perspective is that glycans play a role in every recognised cancer hallmark.
\end{abstract}

\section{INTRODUCTION}

The hallmarks of cancer were originally outlined in 2000 and comprise six biological capabilities acquired during the multi-step development of cancer that allow cancer cells to survive, proliferate and disseminate [1]. As cells evolve progressively to a neoplastic state they acquire a succession of these hallmarks to allow them to become tumourigenic and ultimately malignant. The hallmarks include: sustaining proliferative signalling, evading growth suppressors, resisting cell death, enabling replicative immortality, inducing angiogenesis, and activating invasion and metastasis [1]. Underlying theses hallmarks are genome instability and inflammation which contribute to multiple hallmark functions $[1,2]$. In 2011, more than a decade after the publication of the original cancer hallmarks paper, the next generation of cancer hallmarks were published, and two emerging hallmarks were proposed: reprogramming of energy metabolism and evading immune destruction [3]. The next generation of cancer hallmark traits recognised the 'tumour microenvironment', or the cellular environment in which the tumour exists, as contributing to the acquisition of hallmark traits, adding another dimension of complexity to cancer progression [3].

Aberrant glycosylation in cancer was first described more than 45 years ago [4], and since then it has been well documented that fundamental changes in the glycosylation patterns of cell surface and secreted glycoproteins occur during malignant transformation and cancer progression.
Many of the first cancer-specific antibodies identified were directed against oncofetal antigens expressed on embryonic and tumour cells but not in adult tissues [5]. The importance of glycosylation in cancer is further emphasised by that fact that the majority of FDA-approved tumour markers are glycoproteins or glycan antigens [68]. The expression of cancer associated glycans such as sialyl-Lewis ${ }^{\mathrm{x}}\left(\mathrm{SLe}^{\mathrm{X}}\right)$, Thomsen-nouvelle antigen $(\mathrm{Tn})$, and sialyl-Tn (sTn) antigen have been detected in virtually every cancer type [9].

Growing evidence supports crucial roles for glycosylation during all steps of tumour progression, and it is well established that glycans regulate tumour proliferation, invasion, metastasis and angiogenesis $[10,11]$. Aberrant glycosylation is frequently cited as a hallmark of cancer [11-15], but is notably absent from both the original hallmarks paper [1] and from the next generation hallmarks [3]. The goal of this review is to highlight glycosylation as a mechanistic concept integral to the recognised hallmark traits. Unique to our discussion is our focus on how glycosylation enables acquisition of all the 10 currently accepted hallmarks of cancer cells.

\section{GLYCOSYLATION}

Glycosylation is the enzymatic process that produces glycosidic linkages of saccharides to other saccharides, lipids or proteins [11]. Glycosylation is a frequent and well known post-translational protein modification, and probably much more frequent than phosphorylation. The 
glycome, or complete pattern of glycan modifications in a cell or tissue, is assembled by the synchronised action of numerous glycan modifying enzymes. These enzymes include glycosyltransferases and glycosidases that glycosylate various complex carbohydrates such as glycoproteins, glycolipids and proteoglycans. How much a given protein is glycosylated depends on the presence and frequency of glycosylation sites in the protein sequence, as well as the expression and activities of specific glycosylation enzymes within the cell or tissue [16].

The two most common mechanisms by which glycans are linked to proteins are O-linked glycosylation and N-linked glycosylation. In O-linked glycosylation, sugars are added incrementally to the hydroxyl oxygen of serine, threonine residues [17]. A common type of O-linked glycosylation is initiated via addition of GalNAc, which can then be extended into various different structures. Other types of O-glycans include those attached via O-mannose, and the $\beta$-N-acetylglucosamine (O-GlcNAc) [18-20]. In N-linked glycosylation preassembled blocks of 14 sugars are transferred cotranslationally via the amide group of an asparagine residue and are then further processed [21]. Addition of O-GlcNAc (O-GlcNAcylation) occurs almost exclusively within the cell as an alternative to phosphorylation, while $\mathrm{N}$ - and O-glycans tend to be found at the cell surface as secreted entities, meaning that intra-cellular proteins may be effected by O-GlcNAcylation while interactions at the cell surface often involve $\mathrm{N}$ - glycans and O-glycans [17, 20, 22].

Alterations in glycan composition can aid in various stages of cancer progression. The mechanisms that produce altered glycan structures in cancer cells remain poorly understood, but are believed to involve changes in epigenetics, genetic mutations, misregulated expression of glycosyltransferase and chaperone genes, and mislocalisation of glycosyltransferases [23-26].

\section{SUSTAINING PROLIFERATIVE SIGNALLING}

A fundamental trait of cancer cells is their ability to maintain chronic proliferation [1]. It is well established that glycan expression can play a role in maintaining proliferative signalling. O-GlcNAc modification of proteins has been shown to regulate important cell proteins involved in cell cycle progression including the transcription factor forkhead protein M1 (FoxM1), cyclin D1 [27], and cMYC [28]. Increased MYC O-GlcNAcylation can compete with phosphorylation, stabilising MYC protein and contributing to oncogenesis [28]. The degree of $\mathrm{N}$-glycan branching can also modulate the activity and signalling of growth factor receptors, and can contribute to proliferative signalling [29-32]. Numerous growth factor receptors including EGFR, FGFR, PDGF, MET and IGFR are known to be regulated by glycosylation [33-35].
The extracellular matrix (ECM) imparts the spatial context for the signalling events of various cell surface growth factor receptors, and is composed of a dynamic and complex array of glycoproteins, collagens, glycosaminoglycans and proteoglycans [36]. Glycosylation has been shown to facilitate integrin dependent growth factor signalling to promote cell growth and survival [37, 38], and can also markedly modify the function and signalling of the multifunctional cell surface molecule CD44 $[39,40]$. Ceramide glycosylation in the cell membrane can actively participate in maintaining cancer stem cells by activating c-Src signalling and $\beta$-catenin mediated upregulation of stem cell factors [41]. Proteoglycans also play a role in the biogenesis and recognition of exosomes (secreted vesicles of endosomal origin) which are involved in cell signalling [42].

\section{EVADING GROWTH SUPPRESSORS}

In addition to inducing and maintaining positively acting growth stimulatory signals, cancer cells must also overcome powerful programs that negatively regulate cell proliferation, many of which depend on the actions of tumour suppressor genes. The two canonical suppressors of proliferation, $\mathrm{p} 53$ and RB (retinoblastoma) proteins have both been documented to contain potential glycosylation sites, and their functions may be controlled by dynamic O-GlcNAc modification as well as by phosphorylation [43-45]. O-GlcNAcylation of p53 at residue Ser149 is thought to promote its tumour suppressor activity by inhibiting its phosphorylation on Thr155 [44, 45]. Examples of gain of function p53 mutants have been widely described [46-48], and in this context it might be possible that O-GlcNAcylation induced stabilisation of gain of function mutant forms of p53 could amplify its pro-oncogenic activity [45].

\section{DEREGULATING CELLULAR ENERGETICS}

A key feature of cancer cells is a shift from oxidative phosphorylation to aerobic glycolysis [49]. Known as the 'Warburg effect', this shift in metabolism is characterised by high rates of glucose and glutamine uptake to cope with the increased energetic and biosynthetic needs of the tumour. The abundance of glucose contributes to increased glycolysis and increased flux through metabolic pathways such as the hexosamine biosynthetic pathway (HBP). The end product of the HBP is UDP-GlcNAc which is a critical metabolite used in O-GlcNAcylation and in both N- and O-glycosylation [50]. O-GlcNAc is elevated in various types of cancer and has itself been described as a hallmark of cancer $[45,51]$. O-GlcNAcylation can act as a 'nutritional sensor', and may provide feedback signals that modulate metabolism in response to changing nutrient status [20, 52, 53]. Several studies have suggested that hyper-O-GlcNAcylation is linked to cancer-associated 
metabolic reprogramming [54]. O-GlcNAc can modify a number of glycolytic enzymes [55-57], including phosphofructokinase 1 (PFK1) which catalyses the rate limiting step in glycolysis [57]. O-GlcNAcylation may also play a role in metabolic reprogramming by regulating transcription factors [58, 59] and c-MYC stability [28].

\section{RESISTING CELL DEATH}

Programmed cell death by apoptosis serves as a natural mechanism to prevent cancer development, and a hallmark of cancer is the ability of malignant cells to evade apoptosis $[1,60]$. Glycans play a key role in many of the processes leading to cell death, and can control intracellular signals and extracellular processes that promote the initiation, execution and resolution of apoptosis [61]. Cancer cells often use their glycosylation machinery to modify glycans on cell death receptors, enabling them to resist apoptosis [61]. Glycosylation can modulate the function of death receptors including Fas (CD95) and TNFR1 (tumour necrosis factor receptor 1) $[62,63]$. The glycosylation of death receptors and their canonical ligands may critically regulate apoptosis by disrupting ligand-receptor interactions [64, 65], modulating the formation of signalling complexes [66], and influencing ligand secretion from effector cells [67]. The apoptotic machinery can be positively or negatively regulated through interactions between glycosylated receptors and glycan binding proteins [68]. Lectins are a family of carbohydrate binding proteins that specifically recognise glycans. Galectin-3 association with Fas can repress apoptotic signals [69], and increase tumour cell survival $[70,71]$.

Cellular accumulation of the glycosphingolipid GD3 contributes to mitochondrial damage and plays a key role in apoptosis [72]. GD3 expression is upregulated in neoplastic cells where it regulates tumour invasion and survival [73]. Although an increase in GD3 would normally induce apoptosis, in glioblastomas addition of an acetyl group to the terminal sialic acid (to produce 9-O-acetyl GD3) makes GD3 unable to induce apoptosis, thus promoting tumour survival [74]. Ceramide accumulation also plays a role in programmed cell death [75]. The glucosylceramide synthase (GCS) enzyme can glycosylate ceramide and blunt its pro-apoptotic activity in cancer cells [76].

\section{ENABLING REPLICATIVE IMMORTALITY}

An essential property of cancer cells is to overcome the normal cellular senescence process resulting from the shortening of telomeres. Telomerase activation is a critical step in carcinogenesis and is thought to occur in over $90 \%$ of cancers [77]. Transcriptional reactivation of the human telomerase reverse transcriptase (hTERT) gene is a major mechanism of cancer-specific activation of telomerase.
Although to date there is no evidence linking glycans to telomerase activation, and glycosylation of hTERT has so far not been reported, there is indirect evidence linking glycosylation to telomerase activation through the glycosylation of the transcription factor c-MYC. $\mathrm{C}-\mathrm{MYC}$ is a direct mediator of telomerase activation and can directly induce hTERT gene expression [78, 79]. The c-MYC protein is known to be glycosylated [80], and has been shown to be stabilised by modification with O-GlcNAc [28]. Levels of O-GlcNAcylation are upregulated in various types of cancer $[45,51]$, as are some of the enzymes involved in the hexosamine biosynthesis pathway [81]. Future studies will help determine whether O-GlcNAc mediated stabilisation of c-MYC can indirectly influence telomerase activation and contribute to replicative immortality.

\section{ACTIVATING INVASION AND METASTASIS}

The development of malignant tumours requires the ability of tumour cells to overcome cell-cell adhesion and then invade surrounding tissue. Mounting evidence suggests that certain glycan structures can affect tumour cell invasiveness, including the ability to disseminate through the circulation and metastasise into distant organs [9]. Cancer cells often have high levels of sialylated glycans [82], which are often associated with malignancy and poor prognosis in patients [83-86]. Increased sialylation can increase local negative charges to physically disrupt cell-cell adhesion, and promote detachment from the tumour mass through electrostatic repulsion [87]. Consistent with this, expression of the cancer-associated sTn-antigen reduces cell adhesion in prostate cancer and increases migration and invasion in breast and gastric carcinoma [88-93]. Similarly, ectopic expression of the sialytransferase ST6GAL1 in breast cancer cells has been shown to reduce cell adhesion [94]. Cancer cells characteristically express proteins with truncated O-glycan structures that are thought to be due to mutations or epigenetic silencing of the COSMC gene $[95,96]$, or to increased expression of ST6GalNAc1 [88]. The immature O-glycophenotype of cancer cells has been directly linked to cancer cell growth and invasion [95].

Glycosylation can also influence the activity and localisation of proteins involved in cell adhesion, including the transmembrane glycoprotein E-cadherin. Over-expression of the enzyme MGAT5 in gastric cancer cells induces E-cadherin mislocalisation from the cell membrane into the cytoplasm $[97,98]$. MGAT5 catalyses $\beta 1,6$ GlcNAc branching of N-glycans on E-cadherin, which in turn leads to non-functional adherens junctions, impairs cell-cell adhesion and downstream signalling, and contributes to invasion and metastasis [22, 97101]. Downregulation of the enzyme MGAT3 in mouse mammary tumours increases cell migration and metastasis but genetic background may modify this effect in human 
breast cancer cells $[22,102,103]$. MGAT3 catalyses the addition of bisecting GlcNAc to complex N-glycans and is thought to influence interactions with galectins, and to regulate the function of some glycoproteins, including growth factor receptors and some adhesion molecules [22].

As well as reducing cell-cell adhesion and aiding dissociation from the primary tumour, glycans can also promote the adhesion of tumour cells. The SLe ${ }^{\mathrm{X}}$ antigen is upregulated in several types of cancer [17, 104], and can promote adhesion of tumour cells to endothelial cells through interactions with selectins, in this way mediating the initial steps in metastasis [11, 82]. Galectin-3 regulates the dynamics of N-cadherin [29], and Galectin-1 binding to CD44 and CD326 can promote attachment to the ECM and endothelial cells [105].

The sialyltransferase ST6GalNAc2 has been identified as a metastasis suppressor in breast cancer cells which is linked to patient survival [106]. Loss of ST6GalNAc2 was found to alter the profile of O-glycans on the cell surface and facilitate Galectin-3 binding, leading to an increased metastatic burden [106]. Glycosylation enzymes may also play a key role in mediating cancer cell passage through the blood brain barrier. GALNT9 (an initiator of O-glycosylation) is frequently epigenetically dysregulated in breast tumours that metastasise to the brain [107]. The sialyltransferase ST6GalNAc5 is normally restricted to the brain, but its expression in breast cancer can specifically mediate metastasis to the brain, highlighting the role of cell-surface glycosylation in organ-specific metastatic interactions [108].

\section{INDUCING ANGIOGENESIS}

Through inducing the process of angiogenesis, development of tumour associated neovasculature enables tumours to acquire nutrients and oxygen as well as the ability to remove metabolic waste including carbon dioxide. The development of vasculature involves growing new endothelial cells and their assembly into tubes (vasculogenesis), and the sprouting (angiogenesis) of new vessels from existing ones. In the adult the vasculature is largely quiescent, but during tumour progression an 'angiogenic switch' is activated causing vasculature to continually sprout new vessels and aid tumour growth [109]. A distinct set of glycosylation related genes has been linked to the angiogenesis process $[110,111]$, and it has become increasingly evident that glycans are integral to different events in the angiogenesis cascade [112].

A key inducer of angiogenesis is vascular endothelial growth factor (VEGF), which signals via receptor tyrosine kinases (VEGFRs) and plays a pivotal role in angiogenesis during development and in cancer. Glycosylation of both VEGF and the VEGFRs is associated with angiogenesis. VEGF levels are upregulated by O-GlcNAcylation [113], and aberrant glycosylation of VEGFR can modulate its interaction with galectins and influence blood vessel growth [112]. Glycans also play a role in angiogenesis by regulating Notch signalling [114], maintaining endothelial cell survival [115], controlling vascular permeability [116], and mediating the connection of blood and lymphatic vessels [117]. Changes in cytokines, growth factors and hypoxic conditions have been shown to alter the endothelial glycome to facilitate binding of galectin-1 and activate pro-angiogenic signalling pathways, raising the possibility that a glycosylation signature could be used to distinguish blood vessels at different stages of tumour progression [118].

Heparan sulfate (HS) proteoglycans are abundantly expressed in the developing and mature vasculature, and play a pivotal role in angiogenesis by facilitating the binding of cell surface pro-angiogenic growth factors [119-121]. HS proteoglycans have been described as 'heavy hitters in the angiogenesis arena' [122], and can modulate angiogenesis by affecting the bioavailability and interaction of heparin-binding VEGFs with VEGFRs [123, 124], and by interacting with anti-angiogenic factors such as endostatin [125]. In ovarian cancer HS has been shown to impact angiogenesis through EGF receptor signalling and influencing the expression of angiogenic cytokines [126].

\section{GENOME INSTABILITY \& MUTATION}

Acquisition of the cancer hallmarks is made possible in part by the development of genomic instability in cancer cells which generates random mutations and chromosomal rearrangements. The accumulation of mutations can be accelerated by disrupting the surveillance systems that normally monitor genomic integrity. The tumor suppressor p53 has long been known to play a central role in maintaining a stable genome [127]. O-GlcNAc and O-phosphate modifications co-ordinately regulate p53 stability and activity [44], and a role for O-GlcNAc in the regulation of DNA damage signalling or repair has been suggested [128]. ATM, a key regulator of DNA damage repair is glycosylated, and studies have indicated a dynamic interplay between phosphorylation and O-GlcNAc in the regulation of the DNA damage pathway which could be linked to genomic instability in cancer [129].

\section{TUMOUR PROMOTING INFLAMMATION}

It has long been recognised that some tumours are densely infiltrated by cells of the immune system and thereby mirror inflammatory conditions in nonneoplastic tissues $[3,130]$. Historically, these immune responses were thought to reflect an attempt by the immune system to eradicate the cancerous cells, but there is now growing evidence that the response has 
an unanticipated paradoxical effect to actually aid in tumorigenesis and cancer progression. Within the tumour microenvironment, inflammation can contribute to multiple hallmark capabilities [2, 3], and plays a role in the proliferation and survival of malignant cells, angiogenesis, metastasis, subversion of adaptive immunity, and response to hormones and chemotherapy [2, 131-134]. Genomic instability can also be induced by inflammatory mediators [2]. Changes in glycan composition are closely associated with inflammation [14], and suggest an intricate relationship between glycosylation and inflammation in cancer progression. The selectin proteins (E-, Pand L-Selectin) are associated with cancer metastasis [135], but also play a key role in the entry of circulating lymphocytes into peripheral lymph nodes and leukocyte emigration into inflamed tissues $[14,136]$. The selectins bind sialylated and fucosylated glycans (such as SLe ${ }^{\mathrm{x}}$ ) which act as 'endothelial zip codes' for the homing of lymphocytes into inflammatory sites [137].

Emerging evidence suggests that key mediators in the inflammatory response may be regulated by glycosylation. NF- $\mathrm{\kappa B}$ is a well-characterised orchestrator of inflammation which induces the expression of inflammatory cytokines [138]. The transcriptional activity of NF- $\kappa \mathrm{B}$ can be regulated by O-GlcNAcylation [139], which is known to be upregulated in multiple cancer types [45]. Similarly, the pro-inflammatory molecule COX2 is also regulated by glycosylation [140], and the efficiency of some COX2 inhibitors is thought to be dependent on COX2 glycosylation state [141]. Interestingly, a diet derived sialic acid called N-glycolylneuraminic acid (Neu5Gc, found primarily in red meat) can be incorporated in human tissues. This can lead to the production of autoantibodies against Neu5Gc and subsequent tumour related inflammation via induction of 'xenosialitis' [142].

As well as glycan involvement in the inflammatory response, the inflammatory microenvironment can also reciprocally mediate changes in the glycan composition of cells, which could contribute to tumour malignancy. Pro-inflammatory cytokines can increase the expression of glycosyltransferases involved in the biosynthesis of cancer-associated antigens in pancreatic and gastric cancer cell lines [143, 144].

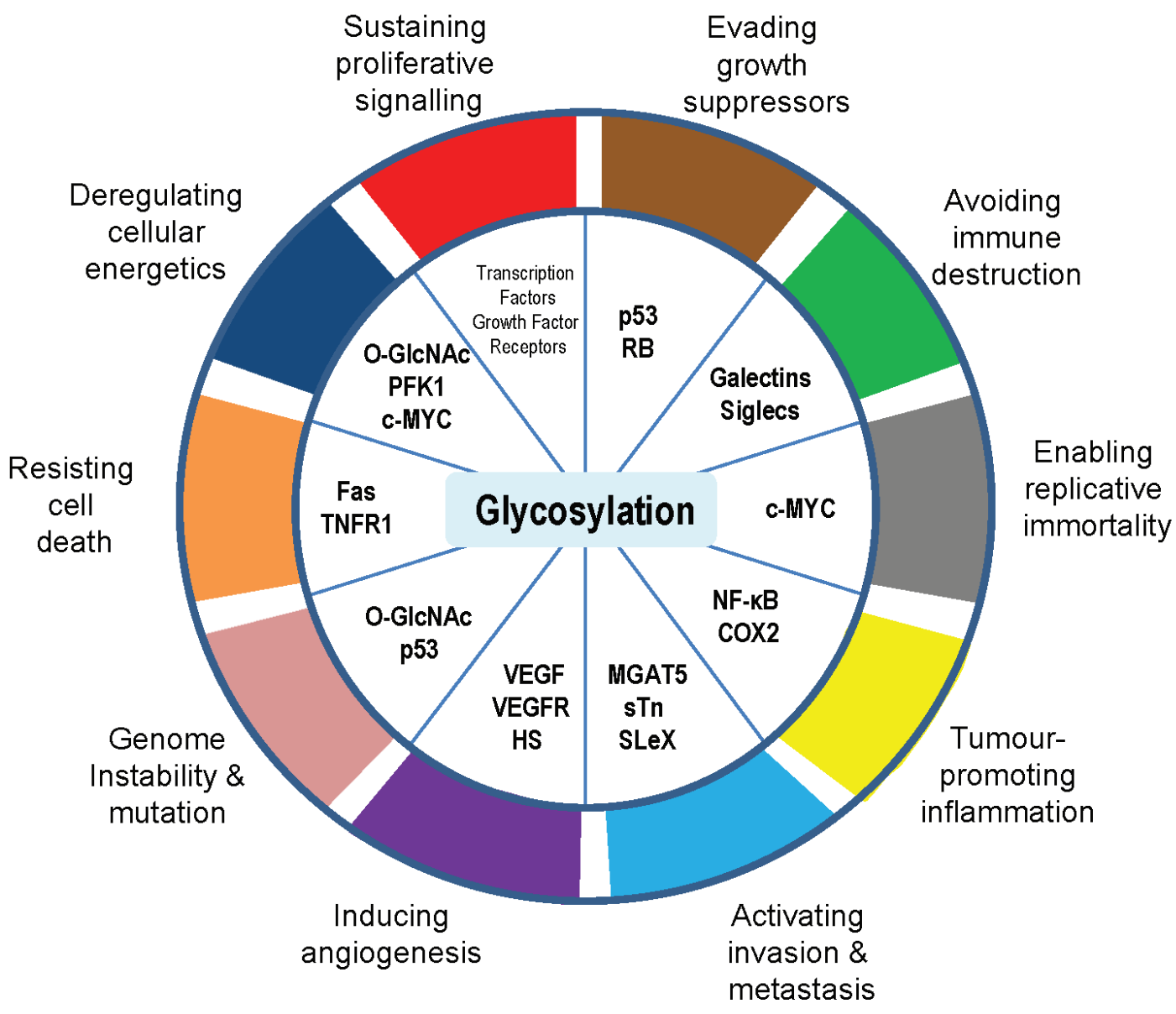

Figure 1: Glycosylation is an enabling characteristic that is causally associated with the acquisition of all the cancer hallmark capabilities. 


\section{AVOIDING IMMUNE DESTRUCTION}

Cancer immune surveillance is thought to inhibit carcinogenesis and is an important host protection process through which transformed cells are eliminated by immune effector cells. Growing evidence suggests that interactions between tumour specific glycans and lectins on immune cells are involved in modulating the tumour microenvironment [145]. Glycans regulate various aspects of the immune response and can interfere with the antitumour response of the immune system, leading to the emergence of cancer cells resistant to the immune system $[11,146]$. This process is mediated by various lectins that bind glycans and regulate immune processes [147, 148]. Galectins can modulate the immune and inflammatory responses and are thought to play a role in helping tumours escape immune surveillance [147, 149]. Siglecs (sialic acid-binding immunoglobulin-type lectins) are transmembrane proteins found on the surface of immune cells. Siglecs are thought to bind to specific glycans and may play a role in escaping immune surveillance in cancer [150]. For example, the alteration of cell surface glycans can modulate siglec-7 mediated cytotoxicity of NK cells and contribute to immune evasion [151]. Glycosylation of $\mathrm{IgG}$ is known to play a role in tumour immune surveillance and is being investigated as a diagnostic marker in several cancer types [152-155]. Targeting altered glycosylation using anticancer vaccines that target tumour associated antigens is an appealing option for cancer treatment $[156$, 157].

\section{CONCLUSIONS}

The hallmarks of cancer comprise biological capabilities acquired during the multi-step development of cancer that allow cancer cells to survive, proliferate and disseminate [1]. Glycosylation is frequently cited as hallmark of cancer but was notably absent from both the original hallmarks and from the updated next generation cancer hallmarks. Here we argue that the process of glycosylation is an enabling characteristic that is causally associated with the acquisition of all the proposed cancer hallmark capabilities (Figure 1), and conversely that the glycan composition of cancer cells can in turn be influenced by the other hallmarks. Glycans have roles in cancer cell signalling, tumour cell dissociation and invasion, cell-matrix interactions, angiogenesis, metastasis and immune modulation. Recognition of the widespread applicability of glycosylation to the cancer hallmarks will increasingly affect the development of new means to treat human cancer.

\section{ACKNOWLEDGMENTS}

This work was funded by Prostate Cancer UK (PG12-34), The J. G. W Patterson Foundation, The
Wellcome Trust (grant numbers WT080368MA and WT089225/Z/09/Z) and BBSRC (grant BB/1006923/1 and BB/J007293/1) and Breast Cancer Now (grant number 2014NovPR355).

\section{CONFLICTS OF INTEREST}

The authors declare no conflict of interest.

\section{REFERENCES}

1. Hanahan D and Weinberg RA. The hallmarks of cancer. Cell. 2000; 100:57-70.

2. Colotta F, Allavena P, Sica A, Garlanda C and Mantovani A. Cancer-related inflammation, the seventh hallmark of cancer: links to genetic instability. Carcinogenesis. 2009; 30:1073-1081.

3. Hanahan D and Weinberg RA. Hallmarks of cancer: the next generation. Cell. 2011; 144:646-674.

4. Meezan E, Wu HC, Black PH and Robbins PW. Comparative studies on the carbohydrate-containing membrane components of normal and virus-transformed mouse fibroblasts. II. Separation of glycoproteins and glycopeptides by sephadex chromatography. Biochemistry. 1969; 8:2518-2524.

5. Feizi T. Carbohydrate antigens in human cancer. Cancer Surv. $1985 ;$ 4:245-269.

6. Hammarstrom S. The carcinoembryonic antigen (CEA) family: structures, suggested functions and expression in normal and malignant tissues. Seminars in cancer biology. 1999; 9:67-81.

7. Moss EL, Hollingworth $\mathrm{J}$ and Reynolds TM. The role of CA125 in clinical practice. J Clin Pathol. 2005; 58:308-312.

8. Gilgunn S, Conroy PJ, Saldova R, Rudd PM and O'Kennedy RJ. Aberrant PSA glycosylation - a sweet predictor of prostate cancer. Nat Rev Urol. 2013; 10:99107.

9. Hauselmann I and Borsig L. Altered tumor-cell glycosylation promotes metastasis. Front Oncol. 2014; 4:28.

10. Fuster MM and Esko JD. The sweet and sour of cancer: glycans as novel therapeutic targets. Nat Rev Cancer. 2005; 5:526-542.

11. Pinho SS and Reis CA. Glycosylation in cancer: mechanisms and clinical implications. Nat Rev Cancer. 2015; 15:540-555.

12. Meany DL and Chan DW. Aberrant glycosylation associated with enzymes as cancer biomarkers. Clinical proteomics. 2011; 8:7.

13. Tuccillo FM, de Laurentiis A, Palmieri C, Fiume G, Bonelli P, Borrelli A, Tassone P, Scala I, Buonaguro FM, Quinto I and Scala G. Aberrant glycosylation as biomarker for cancer: focus on CD43. Biomed Res Int. 2014; 2014:742831.

14. Dube DH and Bertozzi CR. Glycans in cancer and 
inflammation - potential for therapeutics and diagnostics. Nat Rev Drug Discov. 2005; 4:477-488.

15. de-Freitas-Junior JC and Morgado-Diaz JA. The role of N-glycans in colorectal cancer progression: Potential biomarkers and therapeutic applications. Oncotarget. 2016;7:19395-413. doi: 10.18632/oncotarget.6283.

16. Marth JD and Grewal PK. Mammalian glycosylation in immunity. Nature reviews Immunology. 2008; 8:874-887.

17. Kudelka MR, Ju T, Heimburg-Molinaro J and Cummings RD. Simple sugars to complex disease-mucin-type O-glycans in cancer. Adv Cancer Res. 2015; 126:53-135.

18. Brockhausen I, Yang J, Lehotay M, Ogata S and Itzkowitz S. Pathways of mucin O-glycosylation in normal and malignant rat colonic epithelial cells reveal a mechanism for cancer-associated Sialyl-Tn antigen expression. Biol Chem. 2001; 382:219-232.

19. Ma J and Hart GW. O-GlcNAc profiling: from proteins to proteomes. Clinical proteomics. 2014; 11:8.

20. Slawson $\mathrm{C}$ and Hart GW. O-GlcNAc signalling: implications for cancer cell biology. Nat Rev Cancer. 2011; 11:678-684.

21. Schwarz F and Aebi M. Mechanisms and principles of $\mathrm{N}$-linked protein glycosylation. Current opinion in structural biology. 2011; 21:576-582.

22. Taniguchi $\mathrm{N}$ and Kizuka Y. Glycans and cancer: role of $\mathrm{N}$-glycans in cancer biomarker, progression and metastasis, and therapeutics. Adv Cancer Res. 2015; 126:11-51.

23. Stowell SR, Ju T and Cummings RD. Protein glycosylation in cancer. Annual review of pathology. 2015; 10:473-510.

24. Vojta A, Samarzija I, Bockor L and Zoldos V. Glyco-genes change expression in cancer through aberrant methylation. Biochim Biophys Acta. 2016; 1860:1776-85.

25. Potapenko IO, Luders T, Russnes HG, Helland A, Sorlie T, Kristensen VN, Nord S, Lingjaerde OC, Borresen-Dale $\mathrm{AL}$ and Haakensen VD. Glycan-related gene expression signatures in breast cancer subtypes; relation to survival. Molecular oncology. 2015; 9:861-876.

26. Bard F and Chia J. Cracking the Glycome Encoder: Signaling, Trafficking, and Glycosylation. Trends in cell biology. 2016; 26:379-88.

27. Caldwell SA, Jackson SR, Shahriari KS, Lynch TP, Sethi G, Walker S, Vosseller K and Reginato MJ. Nutrient sensor O-GlcNAc transferase regulates breast cancer tumorigenesis through targeting of the oncogenic transcription factor FoxM1. Oncogene. 2010; 29:2831-2842.

28. Itkonen HM, Minner S, Guldvik IJ, Sandmann MJ, Tsourlakis MC, Berge V, Svindland A, Schlomm T and Mills IG. O-GlcNAc transferase integrates metabolic pathways to regulate the stability of $\mathrm{c}-\mathrm{MYC}$ in human prostate cancer cells. Cancer Res. 2013; 73:5277-5287.

29. Boscher C, Dennis JW and Nabi IR. Glycosylation, galectins and cellular signaling. Current opinion in cell biology. 2011; 23:383-392.

30. Taniguchi N. A sugar-coated switch for cellular growth and arrest. Nat Chem Biol. 2007; 3:307-309.

31. Stanley P. A method to the madness of N-glycan complexity? Cell. 2007; 129:27-29.

32. Lau KS, Partridge EA, Grigorian A, Silvescu CI, Reinhold VN, Demetriou M and Dennis JW. Complex N-glycan number and degree of branching cooperate to regulate cell proliferation and differentiation. Cell. 2007; 129:123-134.

33. Julien S, Bobowski M, Steenackers A, Le Bourhis X and Delannoy P. How Do Gangliosides Regulate RTKs Signaling? Cells. 2013; 2:751-767.

34. Todeschini AR, Dos Santos JN, Handa K and Hakomori SI. Ganglioside GM2-tetraspanin CD82 complex inhibits met and its cross-talk with integrins, providing a basis for control of cell motility through glycosynapse. J Biol Chem. 2007; 282:8123-8133.

35. Park SY, Yoon SJ, Freire-de-Lima L, Kim JH and Hakomori SI. Control of cell motility by interaction of gangliosides, tetraspanins, and epidermal growth factor receptor in A431 versus KB epidermoid tumor cells. Carbohydr Res. 2009; 344:1479-1486.

36. Kim SH, Turnbull J and Guimond S. Extracellular matrix and cell signalling: the dynamic cooperation of integrin, proteoglycan and growth factor receptor. J Endocrinol. 2011; 209:139-151.

37. Paszek MJ, DuFort CC, Rossier O, Bainer R, Mouw JK, Godula K, Hudak JE, Lakins JN, Wijekoon AC, Cassereau L, Rubashkin MG, Magbanua MJ, Thorn KS, Davidson MW, Rugo HS, Park JW, et al. The cancer glycocalyx mechanically primes integrin-mediated growth and survival. Nature. 2014; 511:319-325.

38. Tarbell JM and Cancel LM. The glycocalyx and its significance in human medicine. Journal of internal medicine. 2016; 280:97-113.

39. English NM, Lesley JF and Hyman R. Site-specific de-Nglycosylation of CD44 can activate hyaluronan binding, and CD44 activation states show distinct threshold densities for hyaluronan binding. Cancer Res. 1998; 58:3736-3742.

40. Goupille C, Hallouin F, Meflah K and Le Pendu J. Increase of rat colon carcinoma cells tumorigenicity by alpha(1-2) fucosyltransferase gene transfection. Glycobiology. 1997; 7:221-229.

41. Gupta V, Bhinge KN, Hosain SB, Xiong K, Gu X, Shi R, Ho MY, Khoo KH, Li SC, Li YT, Ambudkar SV, Jazwinski SM and Liu YY. Ceramide glycosylation by glucosylceramide synthase selectively maintains the properties of breast cancer stem cells. J Biol Chem. 2012; 287:37195-37205.

42. Roucourt B, Meeussen S, Bao J, Zimmermann P and David G. Heparanase activates the syndecan-syntenin-ALIX exosome pathway. Cell research. 2015; 25:412-428.

43. Wells L, Slawson C and Hart GW. The E2F-1 associated retinoblastoma-susceptibility gene product is modified by O-GlcNAc. Amino Acids. 2011; 40:877-883.

44. Yang WH, Kim JE, Nam HW, Ju JW, Kim HS, Kim 
YS and Cho JW. Modification of p53 with O-linked $\mathrm{N}$-acetylglucosamine regulates p53 activity and stability. Nat Cell Biol. 2006; 8:1074-1083.

45. Fardini $Y$, Dehennaut $V$, Lefebvre $T$ and Issad $T$. O-GlcNAcylation: A New Cancer Hallmark? Frontiers in endocrinology. 2013; 4:99.

46. Oren $\mathrm{M}$ and Rotter V. Mutant p53 gain-of-function in cancer. Cold Spring Harbor perspectives in biology. 2010; 2:a001107.

47. Kalo E, Kogan-Sakin I, Solomon H, Bar-Nathan E, Shay M, Shetzer Y, Dekel E, Goldfinger N, Buganim Y, Stambolsky P, Goldstein I, Madar S and Rotter V. Mutant p53R273H attenuates the expression of phase 2 detoxifying enzymes and promotes the survival of cells with high levels of reactive oxygen species. J Cell Sci. 2012; 125(Pt 22):55785586.

48. Cooks T, Pateras IS, Tarcic O, Solomon H, Schetter AJ, Wilder S, Lozano G, Pikarsky E, Forshew T, Rosenfeld N, Harpaz N, Itzkowitz S, Harris CC, Rotter V, Gorgoulis VG and Oren M. Mutant p53 prolongs NF-kappaB activation and promotes chronic inflammation and inflammationassociated colorectal cancer. Cancer Cell. 2013; 23:634646.

49. Warburg O. On the origin of cancer cells. Science. 1956; 123:309-314.

50. Wells L, Vosseller K and Hart GW. Glycosylation of nucleocytoplasmic proteins: signal transduction and O-GlcNAc. Science. 2001; 291:2376-2378.

51. Singh JP, Zhang K, Wu J and Yang X. O-GlcNAc signaling in cancer metabolism and epigenetics. Cancer letters. 2015; 356(2 Pt A):244-250.

52. Ferrer $\mathrm{CM}$ and Reginato MJ. Cancer metabolism: cross talk between signaling and O-GlcNAcylation. Methods in molecular biology. 2014; 1176:73-88.

53. Hanover JA, Krause MW and Love DC. Bittersweet memories: linking metabolism to epigenetics through O-GlcNAcylation. Nat Rev Mol Cell Biol. 2012; 13:312321.

54. Ma Z and Vosseller K. Cancer metabolism and elevated O-GlcNAc in oncogenic signaling. J Biol Chem. 2014; 289:34457-34465.

55. Nandi A, Sprung R, Barma DK, Zhao Y, Kim SC, Falck JR and Zhao Y. Global identification of O-GlcNAc-modified proteins. Analytical chemistry. 2006; 78:452-458.

56. Teo CF, Ingale S, Wolfert MA, Elsayed GA, Not LG, Chatham JC, Wells L and Boons GJ. Glycopeptide-specific monoclonal antibodies suggest new roles for O-GlcNAc. Nat Chem Biol. 2010; 6:338-343.

57. Yi W, Clark PM, Mason DE, Keenan MC, Hill C, Goddard WA, 3rd, Peters EC, Driggers EM and Hsieh-Wilson LC. Phosphofructokinase 1 glycosylation regulates cell growth and metabolism. Science. 2012; 337:975-980.

58. Ferrer CM, Lynch TP, Sodi VL, Falcone JN, Schwab LP, Peacock DL, Vocadlo DJ, Seagroves TN and Reginato MJ.
O-GlcNAcylation regulates cancer metabolism and survival stress signaling via regulation of the HIF-1 pathway. Mol Cell. 2014; 54:820-831.

59. Penque BA, Hoggatt AM, Herring BP and Elmendorf JS. Hexosamine biosynthesis impairs insulin action via a cholesterolgenic response. Molecular endocrinology. 2013; 27:536-547.

60. Elmore S. Apoptosis: a review of programmed cell death. Toxicologic pathology. 2007; 35:495-516.

61. Lichtenstein RG and Rabinovich GA. Glycobiology of cell death: when glycans and lectins govern cell fate. Cell death and differentiation. 2013; 20:976-986.

62. Wagner KW, Punnoose EA, Januario T, Lawrence DA, Pitti RM, Lancaster K, Lee D, von Goetz M, Yee SF, Totpal K, Huw L, Katta V, Cavet G, Hymowitz SG, Amler L and Ashkenazi A. Death-receptor O-glycosylation controls tumor-cell sensitivity to the proapoptotic ligand Apo2L/ TRAIL. Nat Med. 2007; 13:1070-1077.

63. Shatnyeva OM, Kubarenko AV, Weber CE, Pappa A, Schwartz-Albiez R, Weber AN, Krammer PH and Lavrik IN. Modulation of the CD95-induced apoptosis: the role of CD95 N-glycosylation. PLoS One. 2011; 6:e19927.

64. Keppler OT, Peter ME, Hinderlich S, Moldenhauer G, Stehling P, Schmitz I, Schwartz-Albiez R, Reutter W and Pawlita M. Differential sialylation of cell surface glycoconjugates in a human $\mathrm{B}$ lymphoma cell line regulates susceptibility for CD95 (APO-1/Fas)-mediated apoptosis and for infection by a lymphotropic virus. Glycobiology. 1999; 9:557-569.

65. Peter ME, Hellbardt S, Schwartz-Albiez R, Westendorp MO, Walczak H, Moldenhauer G, Grell M and Krammer $\mathrm{PH}$. Cell surface sialylation plays a role in modulating sensitivity towards APO-1-mediated apoptotic cell death. Cell death and differentiation. 1995; 2:163-171.

66. Swindall AF and Bellis SL. Sialylation of the Fas death receptor by ST6Gal-I provides protection against Fasmediated apoptosis in colon carcinoma cells. J Biol Chem. 2011; 286:22982-22990.

67. Schneider P, Bodmer JL, Holler N, Mattmann C, Scuderi P, Terskikh A, Peitsch MC and Tschopp J. Characterization of Fas (Apo-1, CD95)-Fas ligand interaction. J Biol Chem. 1997; 272:18827-18833.

68. Liu FT, Yang RY and Hsu DK. Galectins in acute and chronic inflammation. Annals of the New York Academy of Sciences. 2012; 1253:80-91.

69. Fukumori T, Takenaka Y, Oka N, Yoshii T, Hogan $\mathrm{V}$, Inohara H, Kanayama HO, Kim HR and Raz A. Endogenous galectin-3 determines the routing of CD95 apoptotic signaling pathways. Cancer Res. 2004; 64:33763379.

70. Oka N, Nakahara S, Takenaka Y, Fukumori T, Hogan V, Kanayama HO, Yanagawa T and Raz A. Galectin-3 inhibits tumor necrosis factor-related apoptosis-inducing ligandinduced apoptosis by activating Akt in human bladder 
carcinoma cells. Cancer Res. 2005; 65:7546-7553.

71. Mazurek N, Byrd JC, Sun Y, Hafley M, Ramirez K, Burks J and Bresalier RS. Cell-surface galectin-3 confers resistance to TRAIL by impeding trafficking of death receptors in metastatic colon adenocarcinoma cells. Cell death and differentiation. 2012; 19:523-533.

72. De Maria R, Lenti L, Malisan F, d'Agostino F, Tomassini B, Zeuner A, Rippo MR and Testi R. Requirement for GD3 ganglioside in CD95- and ceramide-induced apoptosis. Science. 1997; 277:1652-1655.

73. Malisan F and Testi R. GD3 ganglioside and apoptosis. Biochim Biophys Acta. 2002; 1585(2-3):179-187.

74. Birks SM, Danquah JO, King L, Vlasak R, Gorecki DC and Pilkington GJ. Targeting the GD3 acetylation pathway selectively induces apoptosis in glioblastoma. Neurooncology. 2011; 13:950-960.

75. Mullen TD and Obeid LM. Ceramide and apoptosis: exploring the enigmatic connections between sphingolipid metabolism and programmed cell death. Anti-cancer agents in medicinal chemistry. 2012; 12:340-363.

76. Liu YY, Patwardhan GA, Bhinge K, Gupta V, Gu X and Jazwinski SM. Suppression of glucosylceramide synthase restores p53-dependent apoptosis in mutant p53 cancer cells. Cancer Res. 2011; 71:2276-2285.

77. Liu Y, Wu BQ, Zhong HH, Tian XX and Fang WG. Quantification of alternative splicing variants of human telomerase reverse transcriptase and correlations with telomerase activity in lung cancer. PLoS One. 2012; 7:e38868.

78. Greenberg RA, O’Hagan RC, Deng H, Xiao Q, Hann SR, Adams RR, Lichtsteiner S, Chin L, Morin GB and DePinho RA. Telomerase reverse transcriptase gene is a direct target of c-Myc but is not functionally equivalent in cellular transformation. Oncogene. 1999; 18:1219-1226.

79. Wang J, Xie LY, Allan S, Beach D and Hannon GJ. Myc activates telomerase. Genes Dev. 1998; 12:1769-1774.

80. Chou TY, Hart GW and Dang CV. c-Myc is glycosylated at threonine 58, a known phosphorylation site and a mutational hot spot in lymphomas. J Biol Chem. 1995; 270:18961-18965.

81. Itkonen HM, Engedal N, Babaie E, Luhr M, Guldvik IJ, Minner S, Hohloch J, Tsourlakis MC, Schlomm T and Mills IG. UAP1 is overexpressed in prostate cancer and is protective against inhibitors of N-linked glycosylation. Oncogene. 2015; 34:3744-50.

82. Hakomori S. Glycosylation defining cancer malignancy: new wine in an old bottle. Proc Natl Acad Sci U S A. 2002; 99:10231-10233.

83. Amado M, Carneiro F, Seixas M, Clausen H and SobrinhoSimoes M. Dimeric sialyl-Le(x) expression in gastric carcinoma correlates with venous invasion and poor outcome. Gastroenterology. 1998; 114:462-470.

84. Nakamori S, Kameyama M, Imaoka S, Furukawa H, Ishikawa O, Sasaki Y, Kabuto T, Iwanaga T, Matsushita Y and Irimura T. Increased expression of sialyl Lewisx antigen correlates with poor survival in patients with colorectal carcinoma: clinicopathological and immunohistochemical study. Cancer Res. 1993; 53:3632-3637.

85. Kobayashi H, Terao T and Kawashima Y. Sialyl Tn as a prognostic marker in epithelial ovarian cancer. Br J Cancer. 1992; 66:984-985.

86. Kobayashi H, Terao T and Kawashima Y. Serum sialyl Tn as an independent predictor of poor prognosis in patients with epithelial ovarian cancer. J Clin Oncol. 1992; 10:95101.

87. Seidenfaden R, Krauter A, Schertzinger F, Gerardy-Schahn $\mathrm{R}$ and Hildebrandt H. Polysialic acid directs tumor cell growth by controlling heterophilic neural cell adhesion molecule interactions. Mol Cell Biol. 2003; 23:5908-5918.

88. Munkley J, Oltean S, Vodak D, Wilson BT, Livermore KE, Zhou Y, Star E, Floros VI, Johannessen B, Knight B, McCullagh P, McGrath J, Crundwell M, Skotheim RI, Robson CN, Leung HY, et al. The androgen receptor controls expression of the cancer-associated sTn antigen and cell adhesion through induction of ST6GalNAc1 in prostate cancer. Oncotarget. 2015; 6:34358-34374. doi: 10.18632/oncotarget.6024

89. Munkley J and Elliott DJ. Sugars and cell adhesion: The role of ST6GalNAc1 in prostate cancer progression. Cancer Cell \& Microenvironment. 2016; 3:e1174.

90. Pinho S, Marcos NT, Ferreira B, Carvalho AS, Oliveira MJ, Santos-Silva F, Harduin-Lepers A and Reis CA. Biological significance of cancer-associated sialyl-Tn antigen: modulation of malignant phenotype in gastric carcinoma cells. Cancer letters. 2007; 249:157-170.

91. Ozaki H, Matsuzaki H, Ando H, Kaji H, Nakanishi H, Ikehara Y and Narimatsu H. Enhancement of metastatic ability by ectopic expression of ST6GalNAcI on a gastric cancer cell line in a mouse model. Clin Exp Metastasis. 2012; 29:229-238.

92. Julien S, Adriaenssens E, Ottenberg K, Furlan A, Courtand G, Vercoutter-Edouart AS, Hanisch FG, Delannoy P and Le Bourhis X. ST6GalNAc I expression in MDA-MB-231 breast cancer cells greatly modifies their O-glycosylation pattern and enhances their tumourigenicity. Glycobiology. 2006; 16:54-64.

93. Munkley J. The role of Sialyl-Tn in cancer. International Journal of Molecular Sciences. 2016; 17:275.

94. Lin S, Kemmner W, Grigull S and Schlag PM. Cell surface alpha 2,6 sialylation affects adhesion of breast carcinoma cells. Exp Cell Res. 2002; 276:101-110.

95. Radhakrishnan P, Dabelsteen S, Madsen FB, Francavilla C, Kopp KL, Steentoft C, Vakhrushev SY, Olsen JV, Hansen L, Bennett EP, Woetmann A, Yin G, Chen L, Song H, Bak M, Hlady RA, et al. Immature truncated O-glycophenotype of cancer directly induces oncogenic features. Proc Natl Acad Sci U S A. 2014; 111:E4066-4075.

96. Ju T, Aryal RP, Kudelka MR, Wang Y and Cummings RD. 
The Cosmc connection to the Tn antigen in cancer. Cancer biomarkers : section A of Disease markers. 2014; 14:63-81.

97. Pinho SS, Carvalho S, Marcos-Pinto R, Magalhaes A, Oliveira C, Gu J, Dinis-Ribeiro M, Carneiro F, Seruca R and Reis CA. Gastric cancer: adding glycosylation to the equation. Trends in molecular medicine. 2013; 19:664-676.

98. Pinho SS, Reis CA, Paredes J, Magalhaes AM, Ferreira AC, Figueiredo J, Xiaogang W, Carneiro F, Gartner F and Seruca R. The role of $\mathrm{N}$-acetylglucosaminyltransferase III and $\mathrm{V}$ in the post-transcriptional modifications of E-cadherin. Hum Mol Genet. 2009; 18:2599-2608.

99. Carvalho S, Catarino TA, Dias AM, Kato M, Almeida A, Hessling B, Figueiredo J, Gartner F, Sanches JM, Ruppert T, Miyoshi E, Pierce M, Carneiro F, Kolarich D, Seruca R, Yamaguchi Y, et al. Preventing E-cadherin aberrant $\mathrm{N}$-glycosylation at Asn-554 improves its critical function in gastric cancer. Oncogene. 2016; 35:1619-31.

100. Guo HB, Lee I, Kamar $M$ and Pierce $M$. $\mathrm{N}$-acetylglucosaminyltransferase $\mathrm{V}$ expression levels regulate cadherin-associated homotypic cell-cell adhesion and intracellular signaling pathways. J Biol Chem. 2003; 278:52412-52424.

101. Ihara S, Miyoshi E, Ko JH, Murata K, Nakahara S, Honke K, Dickson RB, Lin CY and Taniguchi N. Prometastatic effect of $\mathrm{N}$-acetylglucosaminyltransferase $\mathrm{V}$ is due to modification and stabilization of active matriptase by adding beta 1-6 GlcNAc branching. J Biol Chem. 2002; 277:16960-16967.

102. Song Y, Aglipay JA, Bernstein JD, Goswami S and Stanley P. The bisecting GlcNAc on N-glycans inhibits growth factor signaling and retards mammary tumor progression. Cancer Res. 2010; 70:3361-3371.

103. Miwa HE, Koba WR, Fine EJ, Giricz O, Kenny PA and Stanley P. Bisected, complex N-glycans and galectins in mouse mammary tumor progression and human breast cancer. Glycobiology. 2013; 23:1477-1490.

104. Ugorski M and Laskowska A. Sialyl Lewis(a): a tumorassociated carbohydrate antigen involved in adhesion and metastatic potential of cancer cells. Acta biochimica Polonica. 2002; 49:303-311.

105. Ito K, Stannard K, Gabutero E, Clark AM, Neo SY, Onturk S, Blanchard H and Ralph SJ. Galectin-1 as a potent target for cancer therapy: role in the tumor microenvironment. Cancer metastasis reviews. 2012; 31(3-4):763-778.

106. Murugaesu N, Iravani M, van Weverwijk A, Ivetic A, Johnson DA, Antonopoulos A, Fearns A, Jamal-Hanjani M, Sims D, Fenwick K, Mitsopoulos C, Gao Q, Orr N, Zvelebil M, Haslam SM, Dell A, et al. An in vivo functional screen identifies ST6GalNAc2 sialyltransferase as a breast cancer metastasis suppressor. Cancer Discov. 2014; 4:304-317.

107. Pangeni RP, Channathodiyil P, Huen DS, Eagles LW, Johal BK, Pasha D, Hadjistephanou N, Nevell O, Davies CL, Adewumi AI, Khanom H, Samra IS, Buzatto VC, Chandrasekaran P, Shinawi T, Dawson TP, et al. The
GALNT9, BNC1 and CCDC8 genes are frequently epigenetically dysregulated in breast tumours that metastasise to the brain. Clinical epigenetics. 2015; 7:57.

108. Bos PD, Zhang XH, Nadal C, Shu W, Gomis RR, Nguyen DX, Minn AJ, van de Vijver MJ, Gerald WL, Foekens JA and Massague J. Genes that mediate breast cancer metastasis to the brain. Nature. 2009; 459:1005-1009.

109. Hanahan D and Folkman J. Patterns and emerging mechanisms of the angiogenic switch during tumorigenesis. Cell. 1996; 86:353-364.

110. Garcia-Vallejo JJ, Van Dijk W, Van Het Hof B, Van Die I, Engelse MA, Van Hinsbergh VW and Gringhuis SI. Activation of human endothelial cells by tumor necrosis factor-alpha results in profound changes in the expression of glycosylation-related genes. J Cell Physiol. 2006; 206:203210.

111. Willhauck-Fleckenstein M, Moehler TM, Merling A, Pusunc S, Goldschmidt $\mathrm{H}$ and Schwartz-Albiez R. Transcriptional regulation of the vascular endothelial glycome by angiogenic and inflammatory signalling. Angiogenesis. 2010; 13:25-42.

112. Croci DO, Cerliani JP, Pinto NA, Morosi LG and Rabinovich GA. Regulatory role of glycans in the control of hypoxia-driven angiogenesis and sensitivity to antiangiogenic treatment. Glycobiology. 2014; 24:1283-1290.

113. Lynch TP, Ferrer CM, Jackson SR, Shahriari KS, Vosseller K and Reginato MJ. Critical role of O-Linked beta-N-acetylglucosamine transferase in prostate cancer invasion, angiogenesis, and metastasis. J Biol Chem. 2012; 287:11070-11081.

114. Benedito R, Roca C, Sorensen I, Adams S, Gossler A, Fruttiger $\mathrm{M}$ and Adams RH. The notch ligands D114 and Jagged 1 have opposing effects on angiogenesis. Cell. 2009; 137:1124-1135.

115. Kitazume S, Imamaki R, Ogawa K, Komi Y, Futakawa S, Kojima S, Hashimoto Y, Marth JD, Paulson JC and Taniguchi N. Alpha2,6-sialic acid on platelet endothelial cell adhesion molecule (PECAM) regulates its homophilic interactions and downstream antiapoptotic signaling. J Biol Chem. 2010; 285:6515-6521.

116. Xu D, Fuster MM, Lawrence R and Esko JD. Heparan sulfate regulates VEGF165- and VEGF121-mediated vascular hyperpermeability. J Biol Chem. 2011; 286:737745 .

117. Fu J, Gerhardt H, McDaniel JM, Xia B, Liu X, Ivanciu L, Ny A, Hermans K, Silasi-Mansat R, McGee S, Nye E, $\mathrm{Ju}$ T, Ramirez MI, Carmeliet P, Cummings RD, Lupu F, et al. Endothelial cell O-glycan deficiency causes blood/ lymphatic misconnections and consequent fatty liver disease in mice. J Clin Invest. 2008; 118:3725-3737.

118. Croci DO, Cerliani JP, Dalotto-Moreno T, MendezHuergo SP, Mascanfroni ID, Dergan-Dylon S, Toscano MA, Caramelo JJ, Garcia-Vallejo JJ, Ouyang J, Mesri EA, Junttila MR, Bais C, Shipp MA, Salatino M and Rabinovich 
GA. Glycosylation-dependent lectin-receptor interactions preserve angiogenesis in anti-VEGF refractory tumors. Cell. 2014; 156:744-758.

119. van Wijk XM, Thijssen VL, Lawrence R, van den Broek SA, Dona M, Naidu N, Oosterhof A, van de Westerlo EM, Kusters LJ, Khaled Y, Jokela TA, Nowak-Sliwinska P, Kremer H, Stringer SE, Griffioen AW, van Wijk E, et al. Interfering with UDP-GlcNAc metabolism and heparan sulfate expression using a sugar analogue reduces angiogenesis. ACS chemical biology. 2013; 8:2331-2338.

120. Fuster MM and Wang L. Endothelial heparan sulfate in angiogenesis. Progress in molecular biology and translational science. 2010; 93:179-212.

121. Stringer SE. The role of heparan sulphate proteoglycans in angiogenesis. Biochem Soc Trans. 2006; 34(Pt 3):451-453.

122. Iozzo RV and San Antonio JD. Heparan sulfate proteoglycans: heavy hitters in the angiogenesis arena. $\mathrm{J}$ Clin Invest. 2001; 108:349-355.

123. Houck KA, Leung DW, Rowland AM, Winer J and Ferrara N. Dual regulation of vascular endothelial growth factor bioavailability by genetic and proteolytic mechanisms. J Biol Chem. 1992; 267:26031-26037.

124. Kawamura H, Li X, Goishi K, van Meeteren LA, Jakobsson L, Cebe-Suarez S, Shimizu A, Edholm D, Ballmer-Hofer $\mathrm{K}$, Kjellen L, Klagsbrun $\mathrm{M}$ and Claesson-Welsh L. Neuropilin-1 in regulation of VEGF-induced activation of p38MAPK and endothelial cell organization. Blood. 2008; 112:3638-3649.

125. Sasaki T, Larsson H, Kreuger J, Salmivirta M, ClaessonWelsh L, Lindahl U, Hohenester E and Timpl R. Structural basis and potential role of heparin/heparan sulfate binding to the angiogenesis inhibitor endostatin. EMBO J. 1999; 18:6240-6248.

126. Cole CL, Rushton G, Jayson GC and Avizienyte E. Ovarian cancer cell heparan sulfate 6-O-sulfotransferases regulate an angiogenic program induced by heparin-binding epidermal growth factor (EGF)-like growth factor/EGF receptor signaling. J Biol Chem. 2014; 289:10488-10501.

127. Lane DP. Cancer. p53, guardian of the genome. Nature. 1992; 358:15-16.

128. Zachara NE, Molina H, Wong KY, Pandey A and Hart GW. The dynamic stress-induced "O-GlcNAc-ome" highlights functions for O-GlcNAc in regulating DNA damage/repair and other cellular pathways. Amino Acids. 2011; 40:793808.

129. Zhong J, Martinez M, Sengupta S, Lee A, Wu X, Chaerkady R, Chatterjee A, O'Meally RN, Cole RN, Pandey A and Zachara NE. Quantitative phosphoproteomics reveals crosstalk between phosphorylation and O-GlcNAc in the DNA damage response pathway. Proteomics. 2015; 15(23):591-607.

130. Dvorak HF. Tumors: wounds that do not heal. Similarities between tumor stroma generation and wound healing. $\mathrm{N}$ Engl J Med. 1986; 315:1650-1659.
131. DeNardo DG, Andreu P and Coussens LM. Interactions between lymphocytes and myeloid cells regulate proversus anti-tumor immunity. Cancer metastasis reviews. 2010; 29:309-316.

132. Grivennikov SI, Greten FR and Karin M. Immunity, inflammation, and cancer. Cell. 2010; 140:883-899.

133. Qian BZ and Pollard JW. Macrophage diversity enhances tumor progression and metastasis. Cell. 2010; 141:39-51.

134. Karnoub AE and Weinberg RA. Chemokine networks and breast cancer metastasis. Breast disease. 2007; 26:75-85.

135. Bendas $G$ and Borsig L. Cancer cell adhesion and metastasis: selectins, integrins, and the inhibitory potential of heparins. Int J Cell Biol. 2012; 2012:676731.

136. Kansas GS. Selectins and their ligands: current concepts and controversies. Blood. 1996; 88:3259-3287.

137. Renkonen J, Tynninen O, Hayry P, Paavonen T and Renkonen R. Glycosylation might provide endothelial zip codes for organ-specific leukocyte traffic into inflammatory sites. Am J Pathol. 2002; 161:543-550.

138. Karin M. Nuclear factor-kappaB in cancer development and progression. Nature. 2006; 441:431-436.

139. Ramakrishnan P, Clark PM, Mason DE, Peters EC, Hsieh-Wilson LC and Baltimore D. Activation of the transcriptional function of the NF-kappaB protein c-Rel by O-GlcNAc glycosylation. Science signaling. 2013; 6:ra75.

140. Sevigny MB, Li CF, Alas M and Hughes-Fulford M. Glycosylation regulates turnover of cyclooxygenase-2. FEBS Lett. 2006; 580(28-29):6533-6536.

141. Sevigny MB, Graham K, Ponce E, Louie MC and Mitchell $\mathrm{K}$. Glycosylation of human cyclooxygenase-2 (COX2) decreases the efficacy of certain COX-2 inhibitors. Pharmacological research. 2012; 65:445-450.

142. Samraj AN, Laubli H, Varki N and Varki A. Involvement of a non-human sialic Acid in human cancer. Front Oncol. 2014; 4:33.

143. Bassaganas S, Allende H, Cobler L, Ortiz MR, Llop E, de Bolos C and Peracaula R. Inflammatory cytokines regulate the expression of glycosyltransferases involved in the biosynthesis of tumor-associated sialylated glycans in pancreatic cancer cell lines. Cytokine. 2015; 75:197-206.

144. Padro M, Mejias-Luque R, Cobler L, Garrido M, PerezGaray M, Puig S, Peracaula R and de Bolos C. Regulation of glycosyltransferases and Lewis antigens expression by IL-1beta and IL-6 in human gastric cancer cells. Glycoconjugate journal. 2011; 28:99-110.

145. Rabinovich GA, van Kooyk Y and Cobb BA. Glycobiology of immune responses. Annals of the New York Academy of Sciences. 2012; 1253:1-15.

146. Perdicchio M, Cornelissen LA, Streng-Ouwehand I, Engels S, Verstege MI, Boon L, Geerts D, van Kooyk Y and Unger WW. Tumor sialylation impedes $\mathrm{T}$ cell mediated anti-tumor responses while promoting tumor associated-regulatory T cells. Oncotarget. 2016; 7:8771-82. doi: 10.18632/ oncotarget. 6822 
147. Rabinovich GA and Toscano MA. Turning 'sweet' on immunity: galectin-glycan interactions in immune tolerance and inflammation. Nature reviews Immunology. 2009; 9:338-352.

148. Macauley MS, Crocker PR and Paulson JC. Siglecmediated regulation of immune cell function in disease. Nature reviews Immunology. 2014; 14:653-666.

149. Liu FT and Rabinovich GA. Galectins as modulators of tumour progression. Nat Rev Cancer. 2005; 5:29-41.

150. Dimitroff CJ. Galectin-Binding O-Glycosylations as Regulators of Malignancy. Cancer Res. 2015; 75:31953202.

151. Hudak JE, Canham SM and Bertozzi CR. Glycocalyx engineering reveals a Siglec-based mechanism for NK cell immunoevasion. Nat Chem Biol. 2014; 10:69-75.

152. Vuckovic F, Theodoratou E, Thaci K, Timofeeva M, Vojta A, Stambuk J, Pucic-Bakovic M, Derek L, Servis D, Rudd P, Wennerstrom A, Aulchenko Y, Farrington S, Perola M, Dunlop M, Campbell H, et al. IgG glycome in colorectal cancer. Clin Cancer Res. 2016; 22:3078-86.

153. Saldova R, Royle L, Radcliffe CM, Abd Hamid UM, Evans R, Arnold JN, Banks RE, Hutson R, Harvey DJ, Antrobus R, Petrescu SM, Dwek RA and Rudd PM. Ovarian cancer is associated with changes in glycosylation in both acutephase proteins and IgG. Glycobiology. 2007; 17:1344-1356.
154. Ruhaak LR, Barkauskas DA, Torres J, Cooke CL, Wu LD, Stroble C, Ozcan S, Williams CC, Camorlinga M, Rocke DM, Lebrilla CB and Solnick JV. The Serum Immunoglobulin G Glycosylation Signature of Gastric Cancer. EuPA open proteomics. 2015; 6:1-9.

155. Kazuno S, Furukawa JI, Shinohara Y, Murayama K, Fujime M, Ueno T and Fujimura T. Glycosylation status of serum immunoglobulin $\mathrm{G}$ in patients with prostate diseases. Cancer medicine. 2016; 5:1137-46.

156. Julien S, Videira PA and Delannoy P. Sialyl-tn in cancer: (how) did we miss the target? Biomolecules. 2012; 2:435466.

157. Slovin SF, Ragupathi G, Adluri S, Ungers G, Terry K, Kim S, Spassova M, Bornmann WG, Fazzari M, Dantis L, Olkiewicz K, Lloyd KO, Livingston PO, Danishefsky SJ and Scher HI. Carbohydrate vaccines in cancer: immunogenicity of a fully synthetic globo $\mathrm{H}$ hexasaccharide conjugate in man. Proc Natl Acad Sci U S A. 1999; 96:5710-5715. 